\title{
The Production of Sporidesmin and Sporidesmolides by Pithomyces chartarum
}

\author{
By J. DONE, P. H. MORTIMER AND A. TAYLOR \\ Animal Research Station, Ruakura, Hamilton, New Zealand \\ AND D. W. RUSSELL \\ Plant Chemistry Division, Department of Scientific and Industrial Research, \\ Palmerston North, New Zealand
}

(Received 29 December 1960)

\section{SUMMARY}

Methods for the assay of sporidesmin and the sporidesmolides were worked out and used in the study of the production of these metabolites by Pithomyces chartarum (Commonwealth Mycological Institute, Kew, England, Herbarium no. 74473) growing on an enriched potato carrot medium. High yields of sporidesmin and the sporidesmolides were associated with high utilization of medium constituents. No increase in the quantity of sporidesmin isolated from unit volume of medium was observed after the third day of incubation, despite further rapid growth of the fungus; by contrast good correlation was observed between the weight of sporidesmolides produced and fungal growth. These results were successfully applied to the production of experimental quantities of these materials.

\section{INTRODUCTION}

Recently the suggestion was made (Percival \& Thornton, 1958; Thornton \& Percival, 1959) that the production of toxic material by a micro-organism growing on pasture flora was an important part of a disease of sheep and cattle which occurs in North Island, New Zealand, and is known as facial eczema. The disease occurs under climatological conditions which are conducive to fungal growth. Sheltered warm low-lying pastures have frequently had a history of facial eczema outbreaks. In a survey Thornton \& Ross (1959) showed that certain micro-organisms were predominant on pastures where the disease commonly occurred. One of these micro-organisms Pithomyces chartarum (Berk. \& Curt.) Ellis'(1960) (syn.Sporidesmium bakeri Syd.; Commonwealth Mycological Institute Herbarium no. 74473) after surface-culture on potato carrot medium for 7 days was fed to sheep. The livers of these animals showed pathological changes similar to those observed in clinical cases of facial eczema (Percival, 1959). Chemical examination (Russell, 1960) of such cultures showed that depsipeptides (Shemyakin, 1960) probably identical with those isolated from cut grass from pastures where facial eczema had occurred (White, 1958) were present. Synge \& White (1959) isolated from ethereal extracts of cultures of this fungus a crystalline material which they named sporidesmin. This material, administered orally to guinea-pigs, produced pathological changes in the livers which resembled those observed when similar experimental animals were fed 


\section{J. Done, P. H. Mortimer, A. Taylor and D. W. Russell}

samples of dried grass from pastures known to have been associated with the disease. The potential importance of factors of this kind seemed to warrant an attempt to find what conditions of laboratory cultivation were conducive to the growth of the fungus and whether these were related to the formation of sporidesmin. As the sporidesmolides belong to a group of natural products which commonly possess antibiotic activity (Shemyakin, 1960) it was also of interest to find whether their appearance in the cultures was related to the production of sporidesmin and to the growth of the mould. Such experiments might find application in pasture management, in comparisons of the ability of different strains of the fungus to produce toxic metabolites and in the production of adequate quantities of sporidesmin and the sporidesmolides for biochemical and pathological comparisons of the disease as observed in the field with that produced experimentally.

\section{METHODS}

Organisms. There is at present some controversy about the nomenclature of the organism used in this work (see Hughes, 1958; Ellis, 1960). With one exception the strain used in the present experiments was disposed by the Commonwealth Mycological Institute (Kew, England) as Sporidesmium bakeri Syd. (Hughes, 1953), C.M.I. Herbarium no. 74473. The name Pithomyces chartarum is used in this paper on the basis of Ellis's (1960) work. Miss J. M. Dingley provided us with a strain of this organism that she had isolated at Mount Albert, Auckland, New Zealand. This strain (Ellis, 1960) was used in the experiments recorded in Table 3.

Inocula. Sterile $0.05 \%(\mathrm{w} / \mathrm{v})$ Lissapol $\mathrm{N}$ samples $(10 \mathrm{ml}$.) were transferred aseptically to a 10- to 21-day culture of the fungus on potato carrot agar prepared from the medium described below diluted to half strength with tap water with omission of the additional glucose. The liquid was washed over the slope until this was thoroughly wetted. The suspension was decanted into a sterile container attached to an automatic pipette and sterile water added to make the spore concentration $5 \times 10^{6}$ spores $/ \mathrm{ml}$. For larger quantities of inocula sterile Lissapol $\mathrm{N}$ solution ( $50 \mathrm{ml}$., $0.05 \%$, w/v; I.C.I. Ltd.) was added to a 21 -day culture of the organism on rye (Secale cereale) and the spore suspension prepared as before. The suspension $(0.1 \mathrm{ml}$.) was inoculated to the medium $(100 \mathrm{ml}$.) and to each milk bottle of rye grain or bran (see below).

Surface cultures. Potatoes $(30 \mathrm{~kg}$.) and carrots $(30 \mathrm{~kg}$.) were scrubbed and cut mechanically into $3 \mathrm{~cm}$. cubes. The mixed vegetables were covered with 60-70 l. tap water in a stainless steel vessel equipped with a stainless steel stirrer (120 rev./ min.) and three $2 \mathrm{~kW}$. immersion heaters. The stirred mixture was boiled for $30 \mathrm{~min}$. after which the semi-solid material was allowed to settle and the supernatant liquor decanted. The liquor was made up to the required volume (about $100 \mathrm{l}$.) and sugar and nitrogen determinations carried out. The sugar concentration was then adjusted to $1 \%(\mathrm{w} / \mathrm{v})$ by adding glucose and the nitrogen content was made to $0.05 \%(\mathrm{w} / \mathrm{v})$ by adding ammonium sulphate. The medium was adjusted to $\mathrm{pH} 5 \cdot 0$ by adding dilute sulphuric acid. After filling the culture vessels the medium was heated at about $120^{\circ}$ for $20 \mathrm{~min}$. All surface cultures were incubated at $24^{\circ} \pm 0.5^{\circ}$ for 7 days.

Cultures on rye grain and on bran. In each of 200 pint milk bottles were put rye grain (75 g.) and tap water (45 ml.) (or $50 \mathrm{~g}$. bran and $20 \mathrm{ml}$. water) and the bottles 
allowed to stand overnight. The bottles were then plugged with non-absorbent cotton wool, the plugs being protected with aluminium foil. The bottles were autoclaved at about $120^{\circ}$ for $2 \mathrm{hr}$. After standing in the incubation room for $48 \mathrm{hr}$. three samples selected at random were removed aseptically, transferred to potato + carrot agar slopes and incubated at $\mathbf{2 4}{ }^{\circ}$ for $\mathbf{7 2} \mathrm{hr}$. These slopes were examined from time to time. Meanwhile, when no obvious contamination was present, the bottles were inoculated and incubated at $24^{\circ} \pm 0 \cdot 5^{\circ}$ for 28 days.

Extraction. After incubation for 28 days $80 \%(\mathrm{v} / \mathrm{v})$ methanol in water $(250 \mathrm{ml}$.) were added to each bottle, the fungus and grain broken up with a stout glass rod and the mixture poured into a stainless steel vessel. The mixture was stirred for $20 \mathrm{hr}$. at room temperature and then filtered through a large nutsche dressed with Terylene cloth (coarse-grade sail cloth available in New Zealand was used, precise specifications not known). The residue that remained on the filter was replaced in the stainless steel vessel, $80 \%(\mathrm{v} / \mathrm{v})$ methanol in water $(50 \mathrm{l}$.) added and the mixture stirred for 3 days at room temperature. The liquid that had passed through the Terylene was filtered through Whatman no. 31 filter paper and the perfectly clear filtrate was evaporated down to $3 \mathrm{l}$. in a cyclone evaporator. The concentration process was operated at $2-5 \mathrm{~mm}$. $\mathrm{Hg}$ pressure, the heating heat-exchanger was maintained at $80^{\circ}$ and the condensing heat-exchanger at $-40^{\circ}$. The rate of flow into the heating heat-exchanger was such that the emergent fluid from this part of the apparatus did not exceed $35^{\circ}$. The concentrate was then extracted with diethyl ether (peroxide free, 1 l.) continuously in a Hilditch-type fat extractor for $18 \mathrm{hr}$. The concentrate may also be extracted by hand in a separating funnel in an efficient fume cupboard but even so the process is hazardous; severe dermatitis was experienced by workers using this technique in the early stages of this work. The ethereal extract was evaporated to dryness in vacuo. The second methanolic extract was processed similarly. Gas chromatographic analysis of the methanolic extracting solvent indicated this to be $60-70 \%(\mathrm{v} / \mathrm{v})$ methanol in water. The average yield at this stage for 20 batches was 1.2 g. sporidesmin as a $10-20 \%(\mathrm{w} / \mathrm{v})$ concentrate. Concentrates of about $20 \%(\mathrm{w} / \mathrm{v})$ were obtained when isopropyl ether was used as the second extractant. The lowest yield was $0.6 \mathrm{~g}$. and the highest $1.9 \mathrm{~g}$. Alumina chromatography of this concentrate, partition of the diethyl ether eluate between $80 \%(v / v)$ methanol in water and light petroleum (b.p. 60-80 ) and finally partition chromatography on Hyflo-supercel with the system carbon disulphide + methanol + water $(5,4,1$, by vol.) as described by Synge $\&$ White (1959), provided crystalline material in $\mathbf{8 0 - 9 0} \%$ overall recovery. This material was used in animal experiments to be described elsewhere.

The rye grain and fungus from the second methanolic extraction was stirred and boiled with methanol (20 1.) for $3 \mathrm{hr}$. and the mixture filtered hot. The hot filtrate was concentrated to $4 \mathrm{l}$. in a cyclone evaporator. The concentration process was operated at $20 \mathrm{~mm} . \mathrm{Hg}$, the heating heat-exchanger was maintained at $110^{\circ}$ and the condensing heat-exchanger at $-40^{\circ}$. The concentrate was kept in the cold room at $2^{\circ}$ for $24 \mathrm{hr}$. and the solid that had separated was collected and dried in vacuo. The average yield for ten batches was $27 \mathrm{~g}$. containing 50-70\% sporidesmolides. Further purification was achieved as described below.

Analytical methods. As only about $50 \%$ of the sporidesmin produced by the growth of Pithomyces chartarum was found in culture filtrates all analyses were 


\section{J. Done, P. H. Mortimer, A. Taylor and D. W. Russell}

done on extracts of culture medium and mycelium. Extracts were prepared as follows. The fungus separated from the culture medium was macerated with Whatman no. 31 filter paper (one $12.5 \mathrm{~cm}$. filter paper $/ 100 \mathrm{~g}$. wet wt. fungus) in a top-drive macerator; the resulting mixture was filtered and the residue sucked dry. The filtrate was added to the culture medium and the residue macerated under diethyl ether (400 ml./500 g. wet wt. residue). This process was repeated three times and the combined ethereal solutions, residual fungus and culture medium were continuously extracted in a Hilditch-type fat extractor for $20 \mathrm{hr}$. At least 11 . of ethereal extract was kept in the boiling flask which was heated in a water bath at $80^{\circ}$; when quantities of culture medium between 5 and 201 . were extracted 21 . of ethereal extract were kept in the boiling flask. Further extraction produced only traces of sporidesmin. The ethereal extract was evaporated almost to dryness at $0^{\circ}$ and the residue cooled to $-80^{\circ}$. The ice and sporidesmolides (about $50 \mathrm{mg}$. of the latter/l. were obtained by this procedure) were collected, washed with diethyl ether and the filtrate and washings evaporated to dryness in a tared vessel in vacuo. The resulting brown gum ( $1 \mathrm{~g} . / 10 \mathrm{l}$.) was assayed by at least two of the following procedures.

Tissue culture toxicity tests. Human malignant epithelial cells (strain HeLa, Gey) were obtained from Mr A. M. Murphy (Auckland General Hospital) in May 1959 and transformed pig kidney cells from Glaxo Laboratories Ltd. in October 1959. The medium described by Murphy \& Worker (1960) was modified by increasing the calf serum content to $10 \%(\mathrm{v} / \mathrm{v})$ and by the addition of penicillin $(6 \mu \mathrm{g} . / \mathrm{ml} .=100 \mathrm{i} . \mathrm{u} . / \mathrm{ml}$. and streptomycin (100 $\mu \mathrm{g} . / \mathrm{ml}$.). Phosphate buffered saline (PBS) was made up with sodium chloride (A.R., $1 \cdot 15$ g.), potassium chloride (A.R., 0.2 g.), disodium hydrogen phosphate (A.R., 1.15 g.), potassium dihydrogen phosphate $(0 \cdot 2$ g.) and water to 1 1. A $0 \cdot 1 \%(\mathrm{w} / \mathrm{v})$ 'Bactotrypsin $1: 250$ ' solution in PBS was used for trypsination. Water for the medium, PBS and trypsin was twice glass-distilled. Stock cultures were maintained in $\mathbf{1 5 0} \mathrm{ml}$. square Pyrex screw-cap bottles and test cultures were grown in $125 \times 16 \mathrm{~mm}$. Pyrex screw-cap test-tubes. After use these vessels were soaked overnight in $5 \%(\mathrm{w} / \mathrm{v})$ potassium hydroxide solution in ethanol; they were then washed in tap water, with dilute hydrochloric acid (about $2 \%, \mathrm{w} / \mathrm{v}, \mathrm{HCl}$ in water) and finally with distilled water.

The medium was decanted from a 7 - to 10-day bottle culture and the cells treated with the trypsin solution (8 ml.). After incubation for 10-15 min. the contents of the bottles were gently mixed and the vessel clamped so that the cells settled in one corner of the base. The supernatant fluid was sucked off and fresh medium $(5 \mathrm{ml}$.) added. A uniform suspension was made by making the cells enter and leave a pipette 5-10 times (the efficiency of a pipette in this operation seems to depend on the characteristics of its tip); then a further $10 \mathrm{ml}$. portion of medium was added. A sample $(0.5 \mathrm{ml}$.) of the suspension was centrifuged at low speed for a few minutes and the cells washed twice with PBS $(2 \times 1 \mathrm{ml}$.). Protein was estimated by the Folin colorimetric method (see below). Medium was then added to the suspension to give a final cell-protein content of $50 \mu \mathrm{g} . / \mathrm{ml}$. and $1 \mathrm{ml}$. amounts were dispensed into the test-tubes, with an automatic pipette, with magnetic stirring of the suspension. In the preparation of small batches the suspension was dispensed by a $5 \mathrm{ml}$. graduated pipette. The tubes were placed in trays and the inclination adjusted until the medium reached $5-6 \mathrm{~cm}$. from the bottom of the tube. The trays were rocked 
gently to obtain a uniform suspension and were incubated at $36^{\circ}$ for $24 \mathrm{hr}$. at which time extracts were added in amounts up to $0.1 \mathrm{ml}$.

Extracts were dissolved in ethanol at $20 \mathrm{mg} . / \mathrm{ml}$., and these solutions were serially diluted with PBS. Doses of $4,2,1,0.5,0.25,0.12$ and $0.06 \mu \mathrm{g}$. were used for extracts from surface cultures and a tenth of these amounts for extracts from rye grain and bran cultures. Sporidesmin was assayed over the range $24,12,6,3,1.5$ and $0.75 \mathrm{~m} \mu \mathrm{g} . / \mathrm{ml}$. from dilutions of a $50 \mu \mathrm{g} . / \mathrm{ml}$. ethanolic solution.

The effects of the test solutions were usually determined by comparing the morphology of the cells in the test cultures with those in the controls after $1,2,3$ and 4 days. The sporidesmin present was assessed on the basis of the least dose that gave a marked effect (least toxic dose). There was usually a clear difference between the effect of this dose and that of half the dose; on the other hand, the effect of twice and four times the dose appeared to be similar.

The estimation of protein in the cultures was based on the method of Oyama \& Eagle (1956) and took account of the modified procedure of Miller (1959). It was found that the more concentrated sodium hydroxide solution of the modified method facilitated dissolution of the cells.

Corneal opacity test. About $10 \mathrm{mg}$. of an extract containing about $1 \%(\mathrm{w} / \mathrm{v})$ sporidesmin (e.g. from a surface culture) was dispersed in $0.5 \mathrm{ml}$. of $1 \%(\mathrm{v} / \mathrm{v})$ 'Tween 80 ' solution (L. Light and Co., Colnbrook, England) in a Griffith's tube; two four-fold serial dilutions were made and $0.05 \mathrm{ml}$. volumes of these solutions applied to the eyeballs of small New Zealand White rabbits (weighing 800-1600 g.) whilst the eyelids were held open and elevated from the eyeball. The instilled material was made to flow over the eyeball and the conjunctival membranes by gentle massage, using the elevated eyelids to disperse the material. On the following day similar amounts of the same dilutions were instilled in like manner. The eye lesions at these concentrations were compared with the lesions observed after instillation of 20,5 and $1.25 \mu \mathrm{g}$. crystalline sporidesmin applied in $1 \%(\mathrm{v} / \mathrm{v})$ ' Tween 80 ' solution in the same way. No reaction was noticed at the greatest dilution; at the smallest dilution congestion of the scleral vessels, with oedema and inflammation of the conjunctival membranes, was observed after 2-3 days. Four to five days after instillation this concentration produced marked corneal opacity which lasted for several weeks. A similar corneal opacity was observed at the intermediate dilution 5- 7 days after instillation. Controls were not normally used because no lesions were observed after instillation of $0.1 \mathrm{ml} .5 \%(\mathrm{w} / \mathrm{v})$ 'Tween 80 ' solution.

Iodometric estimations. The method was essentially the same as that used for penicillin (Clarke, Johnson \& Robinson, 1949). Fifty mg. extract were accurately weighed, dissolved in ethanol and the solution made up to $20 \mathrm{ml}$. with ethanol. A $5 \mathrm{ml}$. volume was treated with $5 \mathrm{ml} .20 \%(\mathrm{w} / \mathrm{v})$ sodium hydroxide solution and the mixture allowed to stand for $15 \mathrm{~min}$. at room temperature. The resulting mixture was cooled in ice-water, acidified with $30 \%(\mathrm{v} / \mathrm{v})$ acetic acid in water, $10 \mathrm{ml} .0 .01 \mathrm{~N}$-iodine added and the excess iodine titrated with standard sodium thiosulphate. Starch must be used for this end-point; otherwise it is obscure because of a yellow pigment which is present in the extract. A further $5 \mathrm{ml}$. volume of the extract solution was acidified with $30 \%(\mathrm{v} / \mathrm{v})$ acetic acid in water, treated with $10 \mathrm{ml} .0 .01 \mathrm{~N}$-iodine and the iodine titrated with standard sodium thiosulphate immediately. Under these conditions $1 \mathrm{ml} .0 .01 \mathrm{~N}$-iodine was equivalent to $\mathbf{0 . 7} \mathrm{mg}$. 


\section{J. Done, P. H. Mortimer, A. Taylor and D. W. Russelu}

sporidesmin and the percentage sporidesmin in the sample was calculated from the expression $(x-y) 280 / z \%$, where $x$ is the titre of the blank, $y$ the titre of the alkalitreated sample and $z$ the weight of the original sample. Sporidesmin frequently crystallizes with one molecule of solvent (Synge \& White, 1959). The conversion factor given here for the iodine titration is based on the non-solvated molecule of molecular weight $\mathbf{4 7 5 \cdot 5}$.

Sporidesmolides. The solvents used were of reagent grade. Activated charcoal (Darco, Grade G. 60) was obtained from the Darco Corporation, New York, U.S.A. The total sporidesmolide fraction, prepared as described by Russell \& Brown (1960), was recrystallized from $70 \%(\mathrm{v} / \mathrm{v})$ acetic acid in water (m.p. 256-259 ${ }^{\circ}$; corr.; $[\alpha]_{D}^{20}=-205^{\circ}, c=1 \%$, chloroform). Diethyl ether for this determination was shaken with excess of the total sporidesmolide fraction for $24 \mathrm{hr}$. and filtered before use. When sufficient mycelium was available $10 \mathrm{~g}$. were used; when less was available, the volumes of the reagents, etc., were all decreased in proportion. The final volume of chloroform filtrate and washings was also adjusted as follows : for 8-10 $\mathrm{g}$. mycelium, $25 \mathrm{ml}$.; 6-8 g., $20 \mathrm{ml}$.; 4-6 g., $15 \mathrm{ml}$.; less than 4 g., $10 \mathrm{ml}$.

The dried mycelial felt was weighed and extracted with methanol in a Soxhlet apparatus for $16 \mathrm{hr}$. The methanol was removed on a rotatory evaporator at $50^{\circ}$ and the residue transferred to a separating funnel in solution in a mixture of methanol $(70 \mathrm{ml}$.), chloroform $(100 \mathrm{ml}$.) and water $(30 \mathrm{ml}$.). The mixture was well shaken, the phases allowed to separate, the lower layer collected and the solvents removed on a rotatory evaporator as before. The residue was dissolved in a mixture of chloroform $(50 \mathrm{ml}$.) and ethanol $(50 \mathrm{ml}$.); then benzene $(50 \mathrm{ml}$.) was added and the solvents once more evaporated. The cooled residue was treated with sporidesmolide-saturated ether $(80 \mathrm{ml}$.), mixed by gentle swirling and allowed to stand at room temperature overnight. The precipitate was collected quantitatively, washed with ether saturated with sporidesmolides and treated with chloroform (about $5 \mathrm{ml}$.) at $50^{\circ}$. Solution of the sporidesmolides was completed by gentle agitation for $1 \mathrm{hr}$. at room temperature. Activated carbon $(0.1 \mathrm{~g}$.) was formed into a pad on the surface of a sintered glass funnel and the chloroform solution (containing suspended particles) of the sporidesmolides was passed through under positive pressure. The vessel that contained the unfiltered chloroform solution and the filter were washed successively with further small quantities of chloroform until the volume of the combined filtrates was $25 \mathrm{ml}$. The solution was mixed and its optical rotation determined. The weight (mg.) of total sporidesmolides $(W)$ was calculated from the expression $W=4.9 \propto V / l$, where $\alpha$ is the observed rotation, $V$ the volume of the solution (mI.) and $l$ the length (dm.) of the solution.

Spore counts were made as follows. The fungus filtered off was washed on the filter with distilled water and dried to constant weight in a vacuum oven at room temperature and $\mathbf{0} \cdot \mathbf{1} \mathrm{mm}$. $\mathbf{H g}$ pressure over solid sodium hydroxide. This material was also used for the determination of the amount of sporidesmolides. A sample (about $50 \mathrm{mg}$.) was weighed and ground with $0.05 \%$ (v/v) Lissapol N solution ( $5 \mathrm{ml}$.) until thoroughly dispersed; a duplicate sample was similarly treated. Several spore counts were done on each suspension by using a haemocytometer. The results given are the average of these counts.

Ash and dry weights. Media and filtered culture fluids were lyophilized in tared flasks to determine dry weights. The resulting solid was dissolved in the minimum 
quantity of distilled water and transferred to tared silica crucibles. Solutions were evaporated to dryness in a desiccator and ashed to constant weight in a muffle furnace at $1000^{\circ}$.

Nitrogen was determined by the Kjeldahl method. The results (Table 4) refer to the total-N in the sample since the digests were not de-proteinized.

Sugars were determined by the method of Hanes (1929).

\section{RESULTS}

Estimations of sporidesmin and sporidesmolides were based on extracted material; thus some information was required about losses during this procedure. The sporidesmolides, because of their insolubility in water, were almost wholly present in fungal tissue. They were high melting point, cyclic depsipeptides, stable under the extraction conditions used and thus unlikely to undergo serious losses during the extraction process. Sporidesmin is unstable in alkaline solution, and parallel experiments showed decreased yields when solutions were held above $40^{\circ}$. Sporidesmin $(5 \%, \mathrm{w} / \mathrm{v}$, extract from a previous batch added in ethanolic solution to an equivalent volume of a bulked surface culture) added to a culture before the extraction process was completely recovered when submitted to the isolation procedure; further extraction of the raffinate gave only traces of sporidesmin. When a rye grain culture had been extracted five times with $80 \%(\mathrm{v} / \mathrm{v})$ methanol in water some sporidesmin remained in the residue as it could be isolated by a sixth extraction. A more rapid extraction was achieved by using $80 \%(\mathrm{v} / \mathrm{v})$ ethanol in water but the extract was considerably cruder. Extraction was similarly facilitated in the case of bran cultures but it was not complete and the crude isolate was only $7 \%$ sporidesmin.

Initially dilutions of fungal extracts were added to completed monolayers of HeLa cells for toxicity tests, but it was found difficult to assess a least toxic dose. Cytopathological effects at higher dilutions were mainly observed in the peripheral cells. The technique was therefore altered so that the cells were in groups when the doses were added. Reproducible results were then obtained. Toxic effects down to about the same concentration of pure sporidesmin were found by visually observed changes in cell morphology and by the more objective criterion of protein formation in cultures (Oyama \& Eagle, 1956). Figure 1 shows the amounts of protein formed in cultures in the presence of different amounts of sporidesmin. The dose of sporidesmin was added in $1 \mathrm{ml}$. medium to $\mathbf{2 4} \mathrm{hr}$. cultures, and the protein estimated 5 days later. Results are expressed in terms of the amount of cell protein formed, that in untreated cultures being taken as 100. A sharp increase in protein formation occurred when doses were less than $3 \mathrm{~m} \mu \mathrm{g}$. A least toxic dose of $3 \mathrm{~m} \mu \mathrm{g}$. was repeatedly observed when using the visual method of assessment; this value has been used in computations of the amounts of sporidesmin in extracts of fungal material. Six fungal extracts were tested using both HeLa and transformed pig kidney cell cultures. The least toxic dose was found to be the same in four cases; in two cases the pig kidney cells dose required was twice the HeLa cell dose in order to produce a marked effect. The general appearance of the pig kidney cells at the least toxic dose concentration was characterized by shrinkage to spindle-shaped cells. HeLa cells by contrast, shrank into irregular shapes. Untreated cells of both lines were of like appearance. 


\section{J. Done, P. H. Mortimer, A. Taylor and D. W. Russell}

Excellent agreement was usually observed (Table 1) when parallel estimations were made with the iodometric procedure and the tissue culture toxicity test. Exceptions to this were interesting and point a moral, for in these cases the biological method indicated that no, or very little, sporidesmin was present. The iodometric procedure must therefore be treated with reserve.

Sporidesmolides were determined by a quantitative adaptation of the normal isolation procedure. The recovery of sporidesmolides was determined by adding known weights of the total sporidesmolide fraction to measured quantities of a

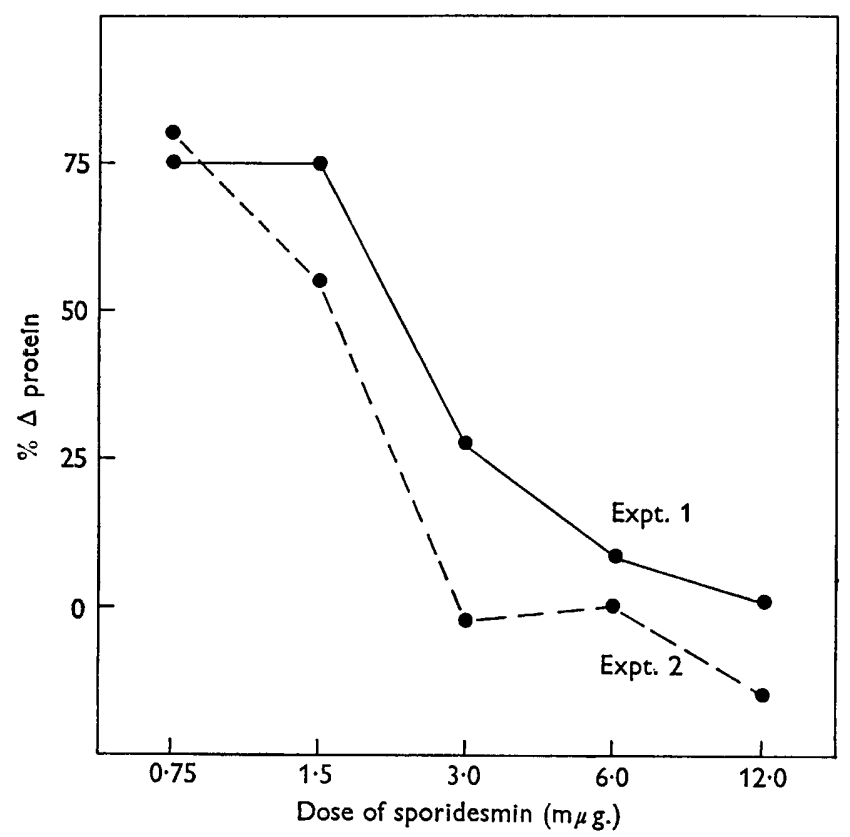

Fig. 1. Response of HeLa cells to sporidesmin doses, by colorimetric measurements of cell protein formed. Doses were added in $1 \mathrm{ml}$. amounts of medium to $24 \mathrm{hr}$. cultures which contained initially $50 \mu \mathrm{g}$. cell protein $/ \mathrm{ml}$. medium. Measurements of protein formed were made on the sixth day. Control (no dose) cultures contained $178 \mu \mathrm{g}$. (Expt. 1) and $68 \mu$ g. (Expt. 2) cell protein. $\% \triangle$ protein $=$ protein formed as a percentage of that of controls.

methanol extract of mycelium. Quantitative recoveries of the added material were obtained. The assay provided a solution containing only sporidesmolides which current work has shown to consist essentially of two depsipeptides, closely related (Russell, 1960). The solutions were determined polarimetrically using the value obtained for the total sporidesmolide fraction of $[\alpha]_{D}^{20}=-205^{\circ}$. The accuracy of the method depended on the constancy of composition of the mixture of sporidesmolides, thus confirmatory data were obtained by determining the weight of sporidesmolides in the solutions. Significant differences were not observed between the gravimetric and polarimetric methods.

The results shown in Table 1 were selected from about 120 batches of surface cultures because the data in these batches were fairly complete and the vessel to vessel variations were small. The sporidesmin results are based on extracts from 
whole batches (usually 50-100 1.). Analyses of medium dry weight were made and also nitrogen, sugar and $\mathrm{pH}$ determinations both on bulked filtered medium at the end of the incubation and on averages of 5-10 sample vessels selected at random. The two series of results agreed well. The mycelium dry weights given were obtained by taking the arithmetical average of the results from 5-10 sample vessels selected at random. In Table 1 the results are expressed as differences between the values obtained before and after incubation; in this way better correlation between the analyses of medium constituents and the amounts of sporidesmin isolated were obtained. In most cases, however, the figure referring to the change in medium dry weight was proportional to the concentration of the starting medium.

Table 1. Utilization of medium constituents and sporidesmin production by Pithomyces chartarum

\begin{tabular}{|c|c|c|c|c|c|c|c|}
\hline \multirow[b]{2}{*}{$\begin{array}{c}\text { Batch } \\
\text { no. }\end{array}$} & \multirow[b]{2}{*}{$\begin{array}{l}\text { Filtered } \\
\text { broth } \\
\Delta \text { dry wt. } \\
\text { (mg./ml.) }\end{array}$} & \multirow[b]{2}{*}{$\begin{array}{c}\Delta \mathrm{N} \\
(\mathrm{mg} \cdot / \mathrm{ml} .)\end{array}$} & \multirow[b]{2}{*}{$\begin{array}{c}\Delta \text { Sugar } \\
(\mathrm{mg} . / \mathrm{ml} .)\end{array}$} & \multirow[b]{2}{*}{$\begin{array}{l}\text { Mycelium } \\
\text { dry wt. } \\
\text { (mg./ml.) }\end{array}$} & \multicolumn{3}{|c|}{ Sporidesmin } \\
\hline & & & & & HeLa & $\begin{array}{c}\text { R.E. } \\
\text { (mg./l.) }\end{array}$ & $\mathbf{I}_{2}$ \\
\hline $73 \mathrm{~A}$ & - & $0 \cdot 12$ & 4.7 & $4 \cdot 0$ & $0 \cdot 3$ & - & $0 \cdot 3$ \\
\hline $63 \mathrm{~B}$ & $10 \cdot 2$ & $0 \cdot 15$ & $5 \cdot 7$ & $3 \cdot 2$ & $0 \cdot 4$ & $0 \cdot 4$ & $0 \cdot 4$ \\
\hline 62 & $18 \cdot 2$ & $0 \cdot 20$ & $5 \cdot 8$ & - & $0 \cdot 4$ & 0.5 & - \\
\hline 44 & $10 \cdot 2$ & $0 \cdot 28$ & $5 \cdot 0$ & $4 \cdot 3$ & 0.5 & $0 \cdot 4$ & - \\
\hline 50 & $21 \cdot 7$ & $0 \cdot 32$ & $7 \cdot 9$ & $6 \cdot 5$ & 0.5 & 0.5 & - \\
\hline $63 \mathrm{~A}$ & $18 \cdot 5$ & $0 \cdot 34$ & $6 \cdot 7$ & $5 \cdot 9$ & 0.7 & - & - \\
\hline 111 & $15 \cdot 7$ & $0 \cdot 34$ & $7 \cdot 0$ & $6 \cdot 1$ & 0.7 & - & $0 \cdot 8$ \\
\hline 68 & $19 \cdot 1$ & 0.55 & $11 \cdot 8$ & 7.9 & $1 \cdot 0$ & - & $1 \cdot 1$ \\
\hline
\end{tabular}

The terms: ' $\Delta$ ' refers to difference between analyses on starting media before inoculation and those on the final filtered broth; ' $N$ ' to nitrogen analyses; 'Mycelium dry wt.' to the total weight of fungal material; 'HeLa' to results obtained by the tissue culture method; 'R.E.' to the corneal opacity test; ' $I_{2}$ ' to results arising from iodometric estimations.

Table 2. Utilization of sugars by Pithomyces chartarum

\begin{tabular}{|c|c|c|c|c|c|}
\hline $\begin{array}{l}\text { Sugar } \\
\text { added }\end{array}$ & $\begin{array}{c}\text { Filtered } \\
\text { broth } \\
\Delta \text { dry wt. } \\
\text { (mg./ml.) }\end{array}$ & $\begin{array}{l}\text { Mycelium } \\
\text { dry wt. } \\
\text { (mg./ml.) }\end{array}$ & $\begin{array}{c}\Delta \text { Sugar } \\
\text { (mg./ml.) }\end{array}$ & $\begin{array}{c}\text { Final } \\
\text { [sugar]* } \\
\text { (mg./ml.) }\end{array}$ & $\begin{array}{c}\Delta \mathbf{N} \\
(\mathrm{mg} \cdot / \mathrm{ml} .)\end{array}$ \\
\hline None & $7 \cdot 3$ & $3 \cdot 1$ & $2 \cdot 14$ & $1 \cdot 10$ & $0 \cdot 22$ \\
\hline Glucose & $9 \cdot 0$ & $4 \cdot 6$ & $5 \cdot 60$ & $1 \cdot 60$ & $0 \cdot 22$ \\
\hline Lactose & $8 \cdot 2$ & $4 \cdot 2$ & 4.99 & $3 \cdot 25$ & $0 \cdot 19$ \\
\hline Galactose & $7 \cdot 3$ & $3 \cdot 2$ & $2 \cdot 10$ & $6 \cdot 10$ & $0 \cdot 20$ \\
\hline Maltose & $9 \cdot 1$ & 4.5 & $5 \cdot 62$ & 1.75 & $0 \cdot 21$ \\
\hline
\end{tabular}

* The square brackets in column 5 indicate concentration; other symbols as in Table 1.

In Table 2 the results of adding $0.5 \%(\mathrm{w} / \mathrm{v})$ of various sugars to the culture before inoculation are summarized. These results are based on repeated experiments which compared groups of three sugars with a control. The addition of the different sugars did not increase the yield of sporidesmin though all sugars except galactose increased the amount of fungal growth during a 7-day period of incubation. Only about half the added lactose was utilized; the effect of adding this sugar on the growth of the fungus was about half that of adding glucose. Since the addition of maltose had a similar effect to the addition of glucose the partial utilization of lactose may be explained by the apparent inability of the organism to use galactose. 


\section{J. Done, P. H. Mortimer, A. Taylor and D. W. Russell}

The addition of ammonium sulphate (Table 3) increased growth in a 7-day fermentation but not the yield of sporidesmin. The analysis of filtrates of spent broth indicated that most of the added nitrogen remained in solution, but it is not known whether this was present as unchanged ammonium salts. It seems unlikely that the increase in growth was due to the sulphur added as other ammonium salts behaved similarly.

Table 3. Effect of adding an inorganic and an organic nitrogen source to Pithomyces chartarum strain 73 a fermentations on potato + carrot media

Adjuvant

None

Ammonium sulphate

Ammonium sulphate

None

Glutamine

Glutamine

Glutamine

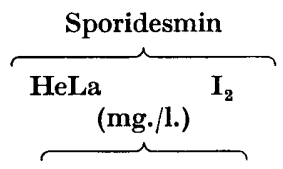

\begin{tabular}{|c|c|}
\hline 0.5 & - \\
\hline 0.5 & - \\
\hline $0 \cdot 6$ & $0 \cdot 7$ \\
\hline $2 \cdot 0$ & $2 \cdot 3$ \\
\hline- & - \\
\hline- & $2 \cdot 8$ \\
\hline $3 \cdot 8$ & $4 \cdot 1$ \\
\hline
\end{tabular}

'Initial N' and 'Final N' refer to analytical values for nitrogen after adding adjuvants and before inoculation and after fermentation for 7 days. Other symbols have the same meaning as before.

Table 4. Sporidesmin isolated after growth of Pithomyces chartarum on media from different plant sources

\begin{tabular}{clcc}
$\begin{array}{c}\text { Batch } \\
\text { no. }\end{array}$ & \multicolumn{1}{c}{ Medium } & $\begin{array}{c}\text { Yield of } \\
\text { (\% dry wt.) }\end{array}$ & $\begin{array}{c}\text { sporidesmin } \\
\text { (mg. } / 100 \mathrm{~g} .\end{array}$ \\
dry medium)
\end{tabular}

Batches 104 and 108 were 28-day fermentations. Similar results were obtained in numerous repeat experiments.

* Corn steep liquor, obtained from Messrs Clifford Love and Co., Sydney, Australia, was collected as the boat berthed and was used the same day.

Semi-quantitative, two dimensional, paper chromatography (kindly carried out by Mr G. R. Russell) of the amino acids present in lyophilically dried samples of culture filtrates taken at $2,3,5$ and 7 days after inoculation showed a steady decrease in the quantities of these substances present. As glutamine appeared to be utilized more rapidly than the other amino acids it was chosen as a source of organic nitrogen. Again most of the nitrogen added remained in the solution at the end of the fermentation (Table 3). Increased growth was observed but also yields of sporidesmin and the sporidesmolides were increased almost in proportion to the quantity of glutamine added. The experiments relating to the addition of glutamine summarized in Table 3 were carried out with a different strain of the organism from that (strain C) used in the rest of this work. This strain (see Methods) produced 
about four times as much sporidesmin when grown under exactly the same cultural conditions as did strain $\mathrm{C}$. Thus a two-fold increase in sporidesmin production, on addition of $0 \cdot 1 \%(\mathrm{w} / \mathrm{v})$ glutamine, was more convincing in the case of the former strain because of the limits of accuracy of the analytical methods.

These results suggested that higher yields of sporidesmin were associated with rich starting medium containing glutamine, so the growth of the fungus and its production of sporidesmin and sporidesmolides was investigated on wet grain and bran.

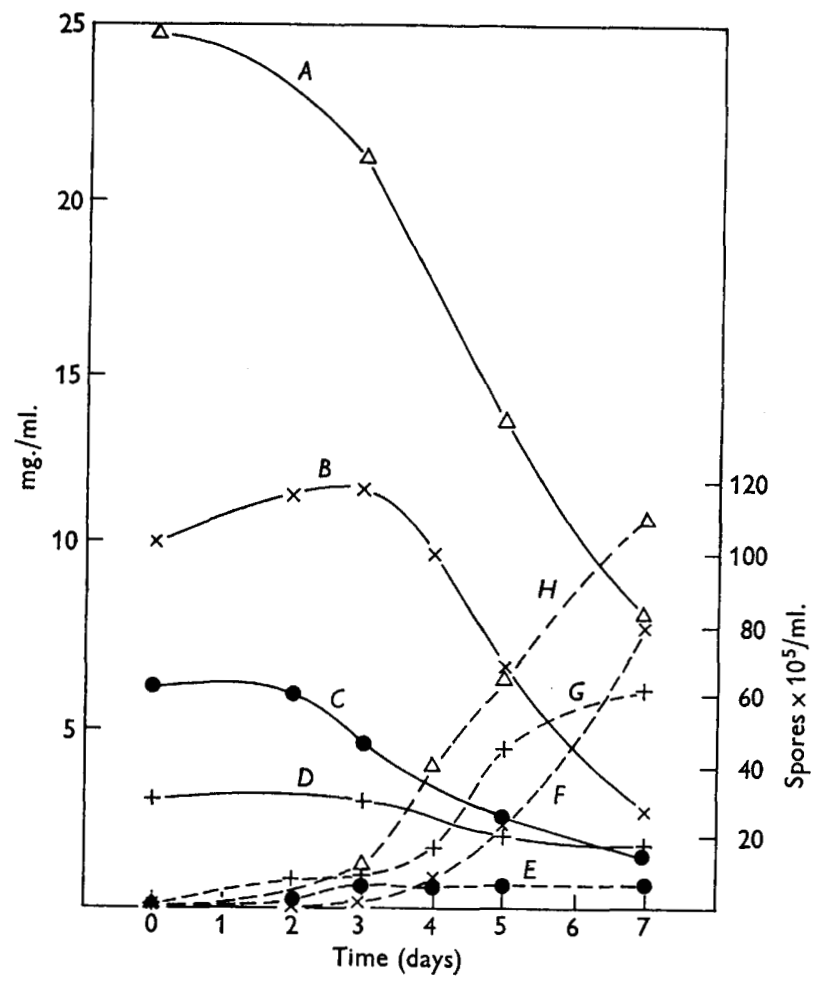

Fig. 2. Utilization of medium constituents and production of sporidesmin and sporidesmolides as a function of culture age. $A$, Dry weight of media; $B$, sugar; $C$, nitrogen $(\times 10) ; D$, ash; $G$, mycelium dry weight; $H$, spore count; $F$, sporidesmolides $(\times 100)$; $E$, sporidesmin $(\times 1000)$.

Lloyd \& Clarke (1959) showed that Pithomyces chartarum grows well on rye grain (Secale cereale) and this has been confirmed in this work. Considerable precautions were required to make sure that residual contaminants were absent after autoclaving. Table 4 compares the yield obtained after culture on rye grain and bran with that obtained on potato carrot medium and corn steep liquor.

Figure 2 summarizes results relating to the change with time of medium dry weight, medium ash values, sugars, nitrogen, fungal growth and spore, sporidesmin and sporidesmolide formation obtained partly from about 120 batches but particularly from six of these batches in which all the analytical data were obtained. The apparent rise in sugar concentration (determined iodometrically) in the first 2-3 days of the fermentation has been noted frequently. In the absence of ammonium salts 


\section{J. Done, P. H. Mortimer, A. Taylor and D. W. Russell}

the $\mathrm{pH}$ value of the medium increased by more than 2 units in a 7 day fermentation. It was found that this gave a good indication of the growth of a culture. The addition of ammonium salts had a buffering effect; changes of only 0.5-1 unit were observed in this case.

Only traces of sporidesmin were isolated from cultures less than $\mathbf{7 2} \mathrm{hr}$. old. After this time the quantity of this metabolite isolated from a given batch did not vary within the limits of accuracy of the analytical methods used. Thus sporidesmin appears in the fermentation at the start of vigorous growth.

The weight of sporidesmolides isolated from unit volume of culture medium is plotted in Fig. 3 as a function of spore numbers in the same volume. Two relations are apparent. Thus the linearity of the relation is independent of the time of fermentation and of the particular experiment.

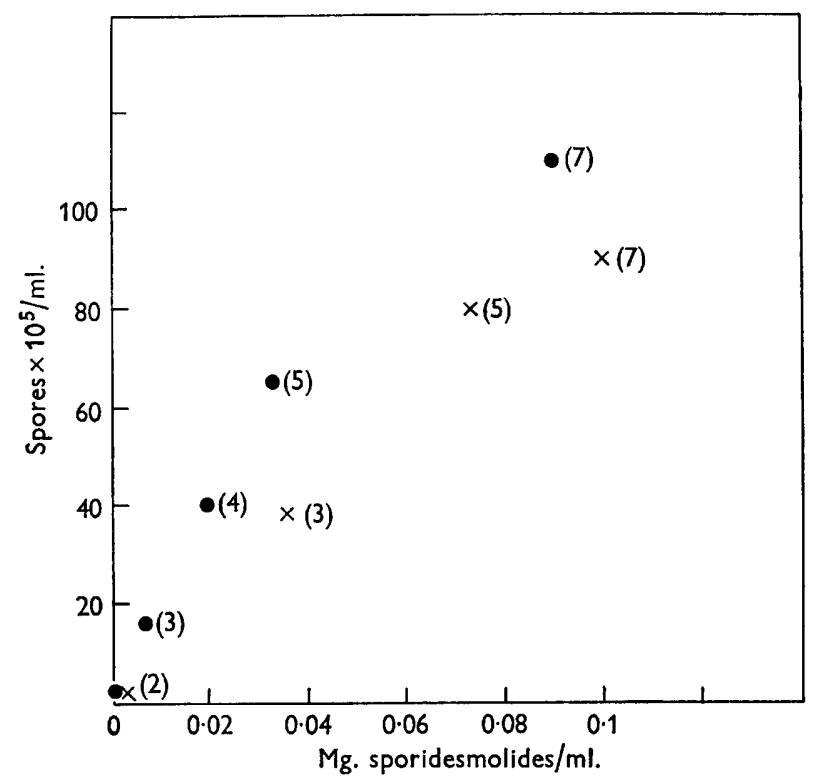

Fig. 3. Spore count $/ \mathrm{ml}$. medium as a function of sporidesmolide production by Pithomyces chartarum. - , Batch no. 111; $\times \times$, batch no. 118. Figures in parentheses indicate the age of culture (days) at which the particular analysis was made.

\section{DISCUSSION}

At the beginning of this work, it was clear that the production of sporidesmin by Pithomyces chartarum growing on potato carrot medium was poor. Antibacterial bioassay could not be used and other methods had to be found. A cytopathological effect of extracts of $\boldsymbol{P}$. chartarum on cultures of HeLa cells was demonstrated by Murphy \& Worker (1960). Evidence that this cytopathological effect was specifically due to sporidesmin was obtained by an examination of least toxic dose values on alternate fractions from the reversed phase partition chromatogram of Synge \& White (1959). Perfect correlation between the highest dilution exhibiting the least toxic dose and a maximum in fraction weight was observed. Side fractions were inactive. The effective concentration of sporidesmin for HeLa cells was about 
$10^{7}$ molecules/cell; this is about the lowest effective cytopathological concentration of the more cytotoxic compounds (colchicine and actinomycin D) studied by Eagle \& Foley (1958).

The application of tissue culture toxicity tests to the examination of many samples from a production programme is severely restricted on a small budget. Recently (Done, Mortimer \& Taylor, 1960) the inflammatory nature of the changes found in the livers of sheep showing clinical facial eczema has been emphasized. It seemed that these phenomena might be due to the presence of a toxin ingested from pasture. Further speculation associated this toxin with sporidesmin. It therefore seemed pertinent to investigate the possibility that inflammatory changes could be induced by extracts containing this material on tissues other than the liver. Such extracts were therefore instilled into rabbit's eyes and were shown to initiate the changes described in the Methods section and shown in Plate 1. Larger amounts than those described in the assay procedure cause correspondingly more severe inflammatory changes which also develop more rapidly. At the highest dose used (40 $\mu \mathrm{g}$.) severe oedema was seen $36 \mathrm{hr}$. after the second instillation and a severe keratitis and ulceration followed with the formation of a sedimented layer of leucocytes in the anterior chamber of the eye. This procedure was used in the earliest stages of this work, before crystalline sporidesmin was available, and proved useful for comparing the biological potency of materials from different sources. It was simple to carry out, and later the results showed good agreement with those obtained by the tissue culture toxicity test and by the iodometric assay.

The possibility was considered that a limiting factor in the formation of sporidesmin by Pithomyces chartarum was the early exhaustion from the medium of a specific precursor of this metabolite. The fermentation displays some similarities to penicillin fermentations and the change in $\mathrm{pH}$ value of the medium suggested that a precursor might be acidic. However extracts of acidified starting medium did not increase the isolated yield of sporidesmin from cultures to which the extracts had been added. An explanation of this negative result might be that the postulated precursor is water soluble and not extractable under the conditions used. The effect of glutamine might be support for this view; however, the latter effect may be analogous to the effect of methionine in the production of cephalosporin $\mathbf{N}$ by Cephalosporium acremonium (C.M.I. Herbarium no. 49,137; Miller, Kelly \& Newton, 1956).

The number of examples of macrocyclic peptide-like substances isolated from cultures of bacteria and fungi is rapidly increasing. In the case of bacteria the compounds are usually true cyclic peptides, e.g. polymyxin $B_{1}$ (Hausmann, 1956; Biserte \& Dautrevaux, 1957). One example of this group, bacitracin, has been shown to be closely associated with the sporulation process of Bacillus licheniformis (Bernlohr \& Novelli, 1960). Two metabolic products, valinomycin (Brockmann \& Geeren, 1957) and amidomycin (Vining \& Taber, 1957) have been isolated from species of Streptomyces; these compounds are macrocycles consisting of eight units of alternative $\alpha$-hydroxy- and $\alpha$-amino acids. The similarity of these compounds to the enniatins studied by Plattner and his co-workers (see, for example, Plattner \& Clauson-Kaas, 1945; Plattner \& Nager, 1948) was pointed out by Young (1957). This group of compounds occurs widely in Fusarium spp. (Lacey, 1950) and they are, structurally, closely related to the sporidesmolides (Russell, 1960). The 


\section{J. Done, P. H. Mortimer, A. Taylor and D. W. Russell}

results in Fig. 3 support the hypothesis (Russell \& Brown, 1960) that the sporidesmolides behave as an impermeable conidial coat. In view of the structural relationship of the whole of this group of substances it seems possible that they may behave generally in this way.

The practical importance of predicting the toxicity of pasture and the elucidation of the possible role of the fungus in connexion with facial eczema perhaps excuse speculation on the application of the results reported in this paper to the understanding of the growth of the organism in the field. It is widely held that pastures become toxic to grazing animals when pasture plants are growing rapidly (see, for example, Filmer, 1958). Should these conditions favour rapid growth of the fungus the results in Fig. 2 suggest that sporidesmin is produced at the onset. Thus techniques such as field counting of spores are unlikely to be of use in forecasting an outbreak of the disease since high spore counts will post-date the onset of toxicity in a pasture. The production of sporidesmin on four different undefined (Table 4) and defined (Ross, 1960) media also suggests that changes in the common species present in pasture will not affect the growth of the organism nor its ability to produce sporidesmin.

This paper was delivered in part before the New Zealand Society for General Microbiology at Dunedin, August 1960. We are indebted to Dr C. P. McMeekan for the provision of facilities. Mr J. W. Ronaldson ran the partition chromatograms; this work will be reported in detail elsewhere. We have had many helpful discussions with Miss J. M. Dingley and Dr R. H. Thornton who have also provided us with cultures. Miss H. Fountain carried out many nitrogen and sugar analyses and Mr G. R. Russell iodometric assays. We thank Miss M. E. Brown, Mrs P. R. Carnegie and $\mathrm{Mr} \mathrm{D}$. A. Lambourne for technical assistance.

\section{REFERENCES}

Bernlohr, R. W. \& Novelli, G. D. (1960). Uptake of bacitracin by sporangia and its incorporation into spores of Bacillus licheniformis. Biochim. biophys. Acta, 41, 541.

Biserte, G. \& Dautrevaux, M. (1957). Structure of polymyxin B. Bull. Soc. Chim. biol. 39, 795.

Brockmann, H. \& Geeren, H. (1957). Valinomycin II; Antibiotika aus Actinomyceten XXVII. Die Konstitution des Valinomycins. Annalen, 603, 216.

Clarke, H. T., Johnson, J. R. \& Robinson, R. (1949). The Chemistry of Penicillin, p. 1026. Princeton: University Press.

Done, J., Mortimer, P. H. \& Taylor, A. (1960). Some observations on field cases of facial eczema: liver pathology and determinations of serum bilirubin, cholesterol, transaminase and alkaline phosphatase. Res. Vet. Sci. 1, 76.

EAGLe, H. \& Foley, G. E. (1958). Susceptibility of cultured human cells to antitumor agents. Ann. N.Y. Acad. Sci. 76, 534.

Ellis, M. B. (1960). Dematiaceous hyphomycetes: 1. Mycol. Papers, no. 76.

Filmer, J. F. (1958). The story of facial eczema research. N.Z. J. Agric. 97, 202.

Hanes, C. S. (1929). An application of the method of Hagedorn and Jensen to the determination of larger quantities of reducing sugars. Biochem. J. 23, 99.

Hausmann, W. (1956). The amino acid sequence of polymyxin $\mathbf{B}_{1}$. J. Amer. chem. Soc. 78, 3663.

Hughes, S. J. (1953). Fungi from the Gold Coast. II. Mycol. Papers, no. 50.

Hughes, S. J. (1958). Revisiones hyphomycetum aliquot cum appendice de nominibus rejiciendis. Canad. J. Bot. 36, 727. 
LACEY, M. S. (1950). The antibiotic properties of fifty-two strains of Fusarium. J. gen. Microbiol. 4, 122.

Lloyd, A. B. \& Clarke, R. T. J. (1959). Spore production by Sporidesmium bakeri on rye-corn (Secale cereale). N.Z. J. Agric. Res. 2, 1084.

Miller, G. A., Kelly, B. K. \& Newton, G. C. F. (1956). Cephalosporin N. United Kingdom Patent 759,624.

Miller, G. L. (1959). Protein determination for large numbers of samples. Anal. Chem. 31, 964.

Murphy, A. M. \& Worker, N. A. (1960). Photosensitivity diseases in New Zealand. XX. The effect of extracts containing the facial eczema toxin on cells in artificial culture. N.Z. J. Agric. Res. 3, 34.

Oyama, V. I. \& Eagle, H. (1956). Measurement of cell growth in tissue culture with a phenol reagent. Proc. Soc. exp. Biol., N.Y. 91, 305.

Percival, J. C. (1959). Photosensitivity diseases in New Zealand. XVII. The association of Sporidesmium bakeri with facial eczema. N.Z. J. Agric. Res. 2, 1041.

Percival, J. C. \& Thornton, R. H. (1958). Relationship between the presence of fungal spores and a test for hepatotoxic grass. Nature, Lond. 182, 1095.

Plattner, Pl. A. \& Clauson-KaAs, N. (1945). Über ein Welke erzeugendes Stoffwechselproduct von Fusarium lycopersici Sacc. Helv. Chim. Acta, 28, 188.

Plattner, Pl. A. \& Nager, U. (1948). Welkstoffe und Antibiotica, 10. Über die Konstitution von Enniatin A. Helv. Chim. Acta, 31, 2192.

Ross, D. J. (1960). A study of the physiology of Pithomyces chartarum, 2. Some factors influencing sporulation in culture. N.Z. J. Sci. 3, 441.

Russell, D. W. (1960). Sporidesmolide I, a metabolic product of Sporidesmium bakeri Syd. Biochim. biophys. Acta, 45, 411.

Russell, D. W. \& Brown, M. C. (1960). Sporidesmolic acid B; a hydroxyacyldipeptide from Sporidesmium bakeri. Biochim. biophys. Acta, 38, 382.

Shemyakin, M. M. (1960). Die Chemie der Depsipeptide. Angew. Chem. 72, 342.

Synge, R. L. M. \& White, E. P. (1959). Sporidesmin: a substance from Sporidesmium bakeri causing lesions characteristic of facial eczema. Chem. \& Ind. 1959, p. 1546.

Thornton, R. H. \& Percrval, J. C. (1959). A hepatotoxin from Sporidesmium bakeri capable of producing facial eczema diseases in sheep. Nature, Lond. 183, 63.

Thornton, R. H. \& Ross, D. J. (1959). The isolation and cultivation of some fungi from soils and pastures associated with facial eczema disease of sheep. N.Z. J. Agric. Res. 2, 1002.

Vining, L. C. \& TABer, W. A. (1957). Amidomycin, a new antibiotic from a Streptomyces species. Canad. J. Chem. 35, 1109.

Whrte, E. P. (1958). Photosensitivity diseases in New Zealand. XIII. Substances isolated from concentrates of facial eczema grass. N.Z. J. Agric. Res. 1, 859.

Young, G. T. (1957). Amino acids, peptides and proteins. Annu. Rep. Chem. Soc. 54, 285. 


\section{J. Done, P. H. Mortimer, A. Taylor and D. W. Russell}

\section{EXPLANATION OF PLATE 1}

(a) A normal rabbit's eye.

(b) Eye showing congestion and proliferation of blood vessels at the corneo-scleral junction. The cornea shows obvious opacity due to migrating leucocytes in its substance. This type of lesion was produced by the instillation of $20 \mu \mathrm{g}$. sporidesmin into the conjunctival sac.

$(c)$ Eye showing changes described in $(b)$ but with more severe corneal opacity. Note especially the white layer of leucocytes which is present in the anterior chamber, having sedimented down at the inner (lower) canthus of the eye. The membrana nictitans is seen to be inflamed and oedematous. This severe eye lesion was produced by the instillation of $40 \mu \mathrm{g}$. sporidesmin. Plate $1(a)$ and Pl. $1(c)$ are respectively the left and right eye of the same animal. 

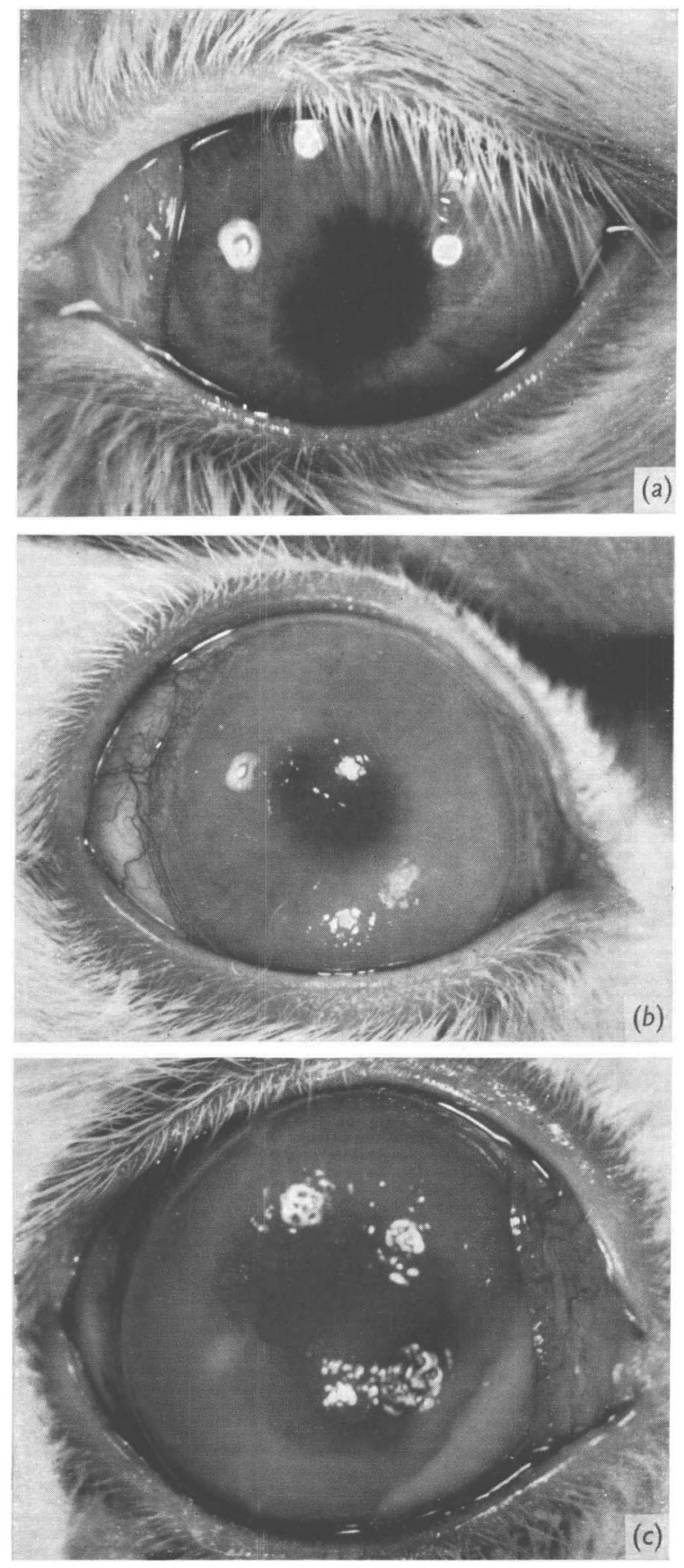

J. DONE, P. H. MORTIMER, A. TAYLOR AND D. W. RUSSELL 